\title{
"El Camino de Santiago" de Alejo Carpentier y la Picaresca
}

\author{
Notre vie est un voyage \\ Dans l'biver et dans le nuit, \\ Nous cherchons notre passage \\ Dans le Ciel où rien ne luit.
}

(L. F. Céline, Voyage du bout de la nuit)

Juan, el romero, el tambor, el estudiante, el indiano ¿cuál es el protagonista de "El Camino de Santiago"? Todos lo son, y ninguno lo es. El protagonista es el conjunto de estos papeles; no es ninguno en particular. Además, el viaje en busca del paraíso imaginado resulta ser una ficción dentro de otra ficción. Ambos, la multiplicidad del protagonista y la ficción del viaje son rasgos de la novela picaresca de los siglos dieciséis y diecisiete que Carpentier ha utilizado para expresar inquietudes modernas.

"El Camino de Santiago" es uno de los relatos de Carpentier que menos se ha estudiado, a pesar de formar parte de la colección Guerra del tiempo que tanta atención crítica ha despertado. ${ }^{1}$ La crítica ha mostrado relaciones entre este relato y las moralidades medievales, pero el estudio que sigue señalará que "El Camino de Santiago" está más vinculado con la novela picaresca que con las moralidades. ${ }^{2}$ Esperamos mostrar cómo el relato se relaciona a las demás obras de Carpentier, cómo se diferencia de ellas, y que las semejanzas y las diferencias giran en torno a su parentesco con el antiguo género picaresco. Es importante tener

1 Cito por Guerra del tiempo (Santiago de Chile: Orbe, 1969).

2 Véase Hugo Rodríguez Alcalá, "Sobre 'El Camino de Santiago' de Alejo Carpentier", en Homendie a Alejo Carpentier, ed. Helmy F. Giacoman (New York: Las Américas, 1970), pp. 243-50; y también Emil Volek, "Dos cuentos de Carpentier: dos caras del mismo método artístico", Nueva narrativa hispanoamericassa, 1, N• 2 (sep. 1971), 7-10. 
presente que Carpentier ve este género desde el punto de vista del siglo veinte, pero que no lo parodia al estilo de Thomas Mann en Félix Krull. No pretendo que "El camino de Santiago" sea novela picaresca, sino que, más importante, refleja el dictamen de Carpentier en cuanto a dicho género y dramatiza los rasgos de tal género que son de interés y consecuencia para el escritor de hoy día. Sin duda, el ambiente del relato es picaresco, ${ }^{3}$ y el hecho de que Carpentier consideró a Juan como un tipo de pícaro es evidente al llamarle romero. Valbuena Prat ha señalado que "romero" muchas veces lleva el sentido de pícaro. ${ }^{4}$ En vista de que Carpentier debiera haberle llamado el peregrino (el que va a Santiago) en vez de romero (el que va a Roma) ${ }^{5}$ es muy probable que empleara el adjetivo con la intención de aludir a la picaresca. Es interesante notar, que como ha apuntado González Echevarría en un artículo suyo inédito, "Notas para una cronología de la obra narrativa de Alejo Carpentier, 1944-54", la primera mención de "El camino de Santiago" fue hecha bajo el título de "El peregrino de Santiago". El hecho de cambiar el nombre de peregrino a romero parece dar fuerza a nuestra teoría del parentesco con la picaresca. Además, el propósito principal de este relato concuerda con el de la novela picaresca, según Carpentier la define en Tientos y diferencias (Montevideo: Arca, 1967): "La picaresca española. .. cumplía con su función cabal de novelística, que consiste en violar constantemente el principio ingenuo de ser relato destinado a causar 'placer estético a los lectores', para hacerse un instrumento de indagación, un modo de conocimiento de hombres y de épocas - modo de conocimiento que rebasa, en muchos casos, las intenciones de su autor" (p. 7). Es obvio que por medio de este relato, Carpentier examina la época de la colonización de América, incorporando así las inquietudes del siglo dieciséis con las del siglo veinte.

\section{II}

Sobresale en "El Camino de Santiago" un rasgo que no es típico de la obra de Carpentier, pero que evoca el género picaresco. Me refiero al desdoblamiento del protagonista. Al fin del relato Juan el Indiano se en-

${ }^{3}$ Sin embargo, a mi parecer no basta sólo el ambiente picaresco que según $A$. Parker, Literature and the Delinquent (Edinburg, 1967), define el género.

4 La novela picaresea espariola, ed. Angel Valbuena Prat (Madrid: Aguilar, 1968), p. 17.

5 Esta es una distinción que hace Dante, Vita Nouva, 40 ("Comentario al soneto XXIII"). 
cuentra con Juan el Romero, con su ser pasado. Empleada por Carpentier, ésta parece una técnica moderna, pero es reflejo de un recurso básico usado en toda novela picaresca, aunque en las tempranas con más sutileza y probablemente sin intención por parte del autor. Diría que el desdoblamiento del protagonista está implícito en cada novela picaresca.

El pícaro es un ser egocéntrico en busca de su posición en la sociedad. Nacido huérfano, ilegítimo, o de padres poco honrados, vive al margen de la sociedad, pero aspira a ser parte de ésta y alcanzar una posición que, por lo menos en su estimación, le dé honra, valor, y sustento. Sin embargo, no le importan los problemas de la sociedad en general sino en lo que le atañen personalmente. A diferencia del héroe moderno, existencial, que busca su identidad, el significado de su vida dentro de sí, el pícato sólo quiere una identidad externa, sólo busca el papel que le toca desempeñar en la vida. Como apunta Robert Alter on Rogue's Progress: Studies in the Picaresque Novel (Cambridge, Mass, 1964), todo pícaro se desplaza por la sociedad aprendiendo y experimentando con varios papeles; los hace y los abandona hasta encontrar uno que le convenga, que satisfaga su orgullo y le dé un sentido de honra, sea ésta falsa o no. ${ }^{6}$ Lazarillo llega a ser pregonero, lo cual para él es una posición en apariencia honrada; ${ }^{7}$ Guzmán alcanza honta y valor al arrepentirse. ${ }^{8}$ Sólo Pablos en El Buscón de Quevedo queda sin una situación que le convenga al terminar el libro. ${ }^{\circ}$

Dado que el pícaro tiene que pasar por varias etapas, posiciones, y niveles de la sociedad en su camino por la vida hacia su destino final, la división interna o el desdoblamiento es implícito. Cada etapa o papel representa un aspecto del ser pícaro. Lazarillo, el mozo del ciego, es un ser distinto del Lázaro, pregonero de vinos, aunque los dos son facetas del mismo personaje. El Guzmán de las galeras al final de la obra no es el Guzmanillo de antes, pero igualmente los dos son parte de una misma totalidad. El protagonista de Histoire de Gil Blas de Santillane de Lesage (Paris: Classiques Garnier, 1962), reconoce que cambia de humor y de espíritu, que sufre una metamorfosis (p. 156). De igual manera, el Buscón dice: "señor, ya soy otro, y otros mis pensamien. tos" (p. 1111).

- Como bien apunta Heckman en "From Telling Stories to Writing", $M L N, 86$ (1971), 858-73, el personaje generalmente no está consciente de la contradicción implícita en su postura $e$ insiste en que ha tenido éxito y en que es feliz.

7 Cito por La novela picaresca española, op. cit., pp. 84-112.

8 Mateo Alemán, Guzmán de Alfaracbe, en La novela picaresca española. op. cit., pp. 234-578.

- Ibid, pp. 1090-1154. 
Este desdoblamiento o división del personaje se manifiesta de varias maneras en "El Camino de Santiago" y en la novela picaresca. Las dos más repetidas son las variaciones de nombre y de ropa, que se ligan a los cambios de oficio, a la vez que sirven de disfraz. En su camino, Juan cambia de Juan, al Romero, a Juan de Amberes, al tambor de Amberes, al Estudiante, y al Indiano. Con estos varios epítetos, Carpentier señala que el nombre puede reflejar sólo un aspecto de la totalidad del ser. ${ }^{10}$ Efectivamente, Juan es todos esos nombres, pero cada nombre sólo revela uno de los muchos papeles que desempeña. Además, el nombre nunca revela la esencia de su ser, sino una característica aparencial y fugitiva. El nombre simplifica el ente complejo y en este sentido, lo enmascara. Como el mundo tiende a juzgar al personaje por su nombre, Juan siempre disfruta del nombre que le conviene: es el Romero porque así le es más fácil encontrar hospedaje; es el Estudiante para engrandecerse ante sus compañeros. Pero, lo curioso es que Carpentier siempre le da el nombre del lugar donde ya no está, o del oficio que ya abandonó. Se llama el Romero al beber vino por primera vez desde su salida de Amberes y al apartarse del camino santo; se llama el Indiano al volver a España de las Indias. Siempre usa lo que era antes para disfrazar lo que es en el presente. El ser siempre muestra lo que se fue, no lo que se es. La novela picaresca refleja un procedimiento similar. Los episodios picarescos siempre indican una metamorfosis progresiva de los varios aspectos del picaro, pero como siempre están escritos desde un punto de vista retrospectivo (o sea, son narrados por el propio personaje a posteriori), muestran lo que era el protagonista; muestran una fase de lo que fue. El ser total al momento de escribir, es siempre una mezcla de todas estas fases pasadas y actuales, a la vez que este ser es una ausencia; ya no es, ya no desempeña ninguno de los papeles pasados. Pero, he aquí la curiosa contradicción del pícaro, porque además de ya no ser al momento de escribir, el picaro se crea al escribir. La escritura le da una existencia, le crea una personalidad y un nuevo papel.

Es evidente que los cambios de indumentaria sirven el mismo fin. Juan viste el hábito de su oficio o el que le conviene para engañar. Continúa vestido de romero después de haber dejado su camino por la misma

10 Se nota que al hablar de tales cambios en el Quijote Leo Spitzer, en "Linguiistic Perspectivism in the Don Quijote", Lingüistic and Literary History (Princeton, 1967), pp. 41-85, apunta que el nombre refleja una especie de perspectivismo porque el nombre sugiere un aspecto del personaje (p. 41). También indica Spitzer que en la Edad Media, cuando los caballeros de los romances sufrían alteraciones espirituales por medio de sus aventuras, la tranformación era subrayada por el nuevo nombre (p. 74, n2). 
razón que sigue llevando el nombre de romero. La esclavina "santificada por hermosas conchas" (p. 33) va descosiéndose en proporción a su aleja. miento del camino santo. En el momento de embarcarse, Juan está vestido de actor, con prendas que designan varios papeles. Es interesante notar el doble juego aquí. Es como si cada prenda señalase un tipo de drama: la casaca del bobo del entremés; la cota de Pilatos que sugiere un drama religioso, un auto sacramental; el sombrero de Arcadio de la comedia italiana. A la vez, estas prendas parecen señalar futuros aspectos de la personalidad de Juan, lo que Ilegará a ser. Busca el paraíso pastoral de Arcadio; es un tipo de Pilatos al negar a sus amigos en el barco; $y$, ¿no es el bobo o el testarudo vizcaino al repetir las mismas mentiras y volver a América? Como el actor, Juan hace el papel que ostenta su vestido. Aquí también parece que Carpentier interpreta la relación que existe entre el comediante y el pícaro; los dos utilizan la vestidura como disfraz para engañar al público.11 Al llegar al fin ante la Virgen, los Juanes tienen "facha de pícaros" (p. 67), y se nota que incluso el diablo siente la necesidad de vestirse para enmascararse. Los dos ejemplos señalan la importancia de la apariencia, y reflejan lo que nos dice Erasmo en Elogio de la locura al recordar el tópico medieval utilizado por Calderón en su Gran teatro del mundo: que la vida es una comedia, por la cual se pasean los hombres, cada uno disfrazándose de otro, desempeñando sus varios papeles hasta la hora de quitarse las máscaras y morir. ${ }^{12}$

Estos cambios de nombre y de vestido, que muestran el desdoblamiento del protagonista y se prestan para enmascarar y engañar, aparecen con frecuencia en las novelas picarescas de los siglos dieciséis y diecisiete, y también son tópico corriente en aquellas obras modernas que se vinculan al género, como Felix Krull de Mann y The Invisible Man de Ellison. La importancia del vestido se destaca desde los primeros episodios del Guzmán de Alfarache. Recordemos su pena al haber perdido la capa y su ansiedad por conseguir nueva indumentaria para entrar en la villa; también describe la minuciosa vestimenta de los mendigos, que se visten según mejor cuadra a su oficio. Guzmán cambia de indumentaria cuando cambia de amo. En Gil Blas también hay una gran preocupación con el ropaje. Gil siente mucha vergüenza al salir de la cárcel por estar tan malamente vestido; su primer proyecto es comprarse hábito de noble, porque reconoce que su posición futura depende de, y debe ser

\footnotetext{
I1 No olvidemos tampoco el inevitable desdoblamiento del comediante que ha notado Diderot en Le paradoxe du comédien.

12 Véase también Ennest Robert Curtius, Europaische literatur und lateinisches Mittekakter (Bern, 1948), especialmente la sección referente a las metáforas teatrales.
} 
reflejada en su vestido. Decide llevar hábito de caballero porque con éste no puede "manquer de parvenir à quelque poste hônnete et lucratif" (p. 54). O sea, va a disfrazarse y a embaucar para alcanzar la posición que desea. Como los otros siempre desempeña el papel que sugiere su ropa. Vemos los mismos procedimientos en Die Landstorzerin Courasche de Grimmelhausen y en El Buscón. La protagonista de Grimmelhausen nunca usa su nombre cristiano y casi siempre se viste de mozo. El Buscón se llama don Pablos en el prólogo para aparecer más valeroso. Como los otros pícaros, el Buscón se viste de noble y toma nombre de noble para alcanzar el amor de una mujer. En todo caso, el pícaro sabe que la gente va a juzgarlo por su nombre y por su vestido.

Así como el pícaro se viste y se nombra para desempeñar el papel que le conviene, también notamos que casi siempre llega a ser la imagen, el reflejo, de otro personaje con quien se ha encontrado en sus varias aventuras. Juan llega a ser una imitación perfecta del indiano con quien se encontró antes. Lo mismo ocurre en la mayor parte de las novelas picarescas, como resultado de la falta de padre honrado a quien imitar; el pícaro tiene que buscar su modelo en otro. Estebanillo nos dice al final de su libro que va a retirarse al estilo de Carlos V, un modelo más bien elevado. ${ }^{13}$ Gil Blas imita a sus varios amos: primero a Silva y al médico y después a los varios amos de la corte. El Buscón trata de imitar a don Diego; Guzmán llega a parecerse a algunos de los religiosos honestos con quienes se encontró. Sin duda, todo pícaro es una imitación por lo menos en apariencia, de otro personaje que ha conocido. Esta tendencia es particularmente evidente en las variaciones modernas de la novela picaresca. Pensemos en Felix Krull que llega a ser reflejo y hasta doble de Luis, Marqués de Venosta, o en Augie March, que tantas veces sigue las huellas de su hermano en la novela de Saul Bellows del mismo nombre (Nueva York, 1953).

Se manifiesta la división interna o desdoblamiento visto en la obra de Carpentier en las charlas entre Juan el Romero y Juan el Indiano. Recordemos que el romero llega a ser indiano, y éste se encuentra con otro Juan el Romero. Estas charlas entre las dos partes de un mismo personaje son rasgos característicos de la novela picaresca. Sin olvidar que hasta cierto punto toda escritura en la primera persona es una dramatización del narrador al hablar consigo mismo, podemos considerar que Guzmán se habla a sí mismo por medio de las digresiones morales. Guz-

$13 \mathrm{Me}$ refiero al protagonista de Vida y becbos de Estebanillo González, hombre de buen bumor, compuesta por él mismo, en la colección de Valbuena Prat, pp. 1720-1848. 
mán, el arrepentido, le habla al Guzmán el pecador, que fue antes tanto como al lector. ${ }^{14}$ Este recurso se ve mucho en Gil Blas: la acción de la novela se detiene repetidas veces mientras Gil se dice: "me dis-je à moimême..." Se nota que con frecuencia estas charlas tratan de una cuestión moral o de una decisión sobre qué camino debe seguir en el futuro.

Esta multiplicidad última del protagonista es evidente en "El Camino de Santiago" cuando se dice que en un sueño Juan "se ve a sí mismo" (p. 58). En un momento de su vida todo pícaro, en efecto todo hombre, se ve a sí mismo. Toda novela picaresca tiene que ser autobiográfica (por esto digo que esta obra no es propiamente picaresca); el narrador tiene que relatar su propia vida al estilo de las confesiones religiosas, porque como apunta la Locura en la obra de Erasmo, nadie puede revelar la verdad sobre uno mejor que uno mismo. Por ello, la novela resulta ser un medio para que el narrador se mire.

\section{III}

Quizá lo que más sobresalga en "El Camino de Santiago" sea la visión cíclica que tanto se ve en la obra de Carpentier. En su obra el viaje es siempre una empresa fútil y se convierte en una trayectoria circular. ${ }^{15} \mathrm{Se}$ habrá notado que el viaje de Juan le devuelve al punto de partida para empezar el mismo viaje de nuevo. La estructura del cuento es lineal a la vez que circular. El motivo del viaje da la impresión de adelanto, de progreso, pero sólo es ilusión. La estructura del cuento se perfila de la siguiente manera:

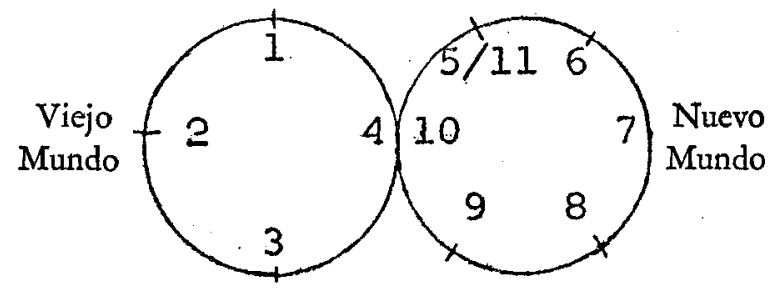

Hay dos ciclos distintos con un punto común. (Los números indican los capítulos y las varias etapas del ciclo). En los primeros dos capítulos Juan es soldado en Flandes; al final del segundo sueña con el Duque

14 Es un hecho que también ha notado Francisco Rico, La novela picaresca y el punto de vista (Barcelona, 1970), pp. 59-91.

1.5 Véase el artículo de Roberto González Echevarría, "'Semejante a la noche' de Alejo Carpentier: historia-ficción", $M N L, 87$ (1972), pp. 272-285. 
y jura empezar su peregrinaje, lo cual se desarrolla en el capitulo tres. Al comenzar el cuarto capítulo Juan ha llegado a Burgos, y es aquí donde deja el camino santo para ir al Nuevo Mundo. Entonces, en vez de terminar el ciclo empezado (o sea, en vez de continuar a Santiago para después volver a Flandes como ha prometido) sale de este ciclo y entra en el otro (que se representa con el segundo círculo). Parece evidente que se pueden distinguir los dos ciclos por medio de los dos mundos: el Nuevo, y el Viejo cuyo ciclo nunca llega a terminar. El punto común, Burgos, descrito por Carpentier es una mezcla de los dos mundos. En Burgos se encuentra la feria medieval europea, además del indiano y los mitos recién llegados de América. En el capítulo cinco se describe la preparación para el viaje y la llegada de Juan a Cuba. Se nota que Sevilla también forma más parte del Nuevo Mundo que del Viejo - recuérdese que allí todos vivían con el ojo atento al Nuevo Mundo. Los capítulos seis, siete, y ocho tratan de la vida de Juan en el Nuevo Mundo y al final del octavo sueña el protagonista de nuevo y jura volver al Camino de Santiago. El paralelo entre este capítulo y el segundo es explícito. Los dos terminan con un sueño que le arroja al peregrinaje. También un capítulo de viaje sigue a cada sueño, y los dos viajes llevan a Juan a Burgos; en otras palabras, vuelve al punto de partida y completa el ciclo. Cada vez que llega a este punto, compartido por los dos ciclos, tiene que escoger: seguir el camino santo y volver luego a Flandes o repetir el camino a América. Se decide en favor del segundo y se junta con otro romero que ha andado la ruta del primer ciclo, y que ya le va a seguir en el segundo. Como se puede ver por el dibujo, el capítulo once es paralelo al quinto, y el relato sugiere que tal ciclo continuará siempre. Se puede añadir aqui que este movimiento circular resulta de la continua búsqueda del paraíso terrenal. Lo busca en el Nuevo Mundo y al no encontrarlo allí, añota la vida del Viejo Mundo como si éste fuera el paraíso perdido. Pero, al volver otra vez piensa en el paraíso de América. Como dice el narrador de Los pasos perdidos, "yo me asombraba... de la diferencia que existía entre el mundo añorado por mi padre $y$ el que me había tocado conocer... no había fuga posible, fuera de lo imaginario". ${ }^{16}$

Este tema del viaje en el relato de Carpentier refleja otro rasgo de la picaresca. Toda novela picaresca tiene la estructura de un viaje, el cual no sólo le da forma sino sentido. Ya hemos señalado la estructura circular del viaje de Juan, y parece indiscutible que gran parte de las novelas

1o Alejo Carpentier, Los pasos perdidos (Barcelona, 1971), p 92. 
picarescas también tienen una estructura circular. Los viajes hechos presentan nuevos lugares donde vivir, pero en sí no efectúan cambios, porque todo sitio es básicamente igual. El Buscón lo suma diciendo: "determiné... de pasarme a Indias con ella, a ver si mudando mundo y tierra mejoraría mi suerte. $Y$ fueme peor, pues nunca mejora su estado quien mude solamente de lugar y no de vida y costumbre" (p. 1153). Al fin y al cabo el ser picaresco ha cambiado poco en esencia al terminar su libro. Sin duda muy pocas veces alcanza el pícaro la fama y fortuna que persigue en sus viajes; pocas veces ha logrado alterar mucho su posición original.

En la mayor parte de estas novelas debe verse el viaje no sólo en su sentido literal sino también en su sentido figurativo o simbólico. Como ya señalamos, en "El Camino de Santiago" el viaje de Juan representa la búsqueda de un paraíso que en realidad no existe. Claudio Guillén ha dicho que todo pícaro aprende que no hay un paraíso pastoral más allá de la sociedad, ${ }^{17}$ y yo añadiría que el viaje de la novela picaresca, además de simbolizar la búsqueda de una situación en la sociedad, también señala la busca de este Paraíso, y que el carácter circular del viaje es resultado de la inexistencia de la utopía. En este sentido toda novela picaresca es literatura del fracaso, porque, con la posible excepción de Guzmán, el pícaro no encuentra su tierra prometida. Sólo encuentra una vida que quizá aventaja la previa en cuanto a las apariencias, pero no en cuanto a las esencias. Lazarillo deja su casa en búsqueda del Paraíso, pero pronto se da cuenta de que "escapa del trueno para dar en el relámpago" (p. 91). Guzmán viaja a Italia en busca de presuntos familiares "nobles" que le provean un mundo mejor donde vivir. Don Pablos, como Juan, se va a América en busca de su utopía. O sea, el viaje picaresco casi siempre resulta en desengaño al no encontratse el Paraíso y regresar a un punto bien cerca al de partida. Carpentier recalca esta característica con su descripción del desengaño que sufre Juan al llegar al Nuevo Mundo $\mathrm{y}$ al encontrar los mismos chismes y odios que en el Viejo. Es evidente que, como en todo pícaro, no importa a dónde vaya Juan; no puede escaparse de su época, de su sociedad, ni de sí mismo, lo cual se destaca en el hecho de que al llegar a Cuba toca en su tambor la misma marcha que tocó cuando su compañía llegó a Amberes para hacer guerra a los herejes. Como apunta Peter Earle con respecto a La vorágine, la febril odisea del protagonista sólo conduce a la degeneración y fracaso finales. ${ }^{18}$

17 "Toward a Definition of the Picaresque", Literature as System: Essays Toward the Theory of Literary History (Princeton: New Jersey, 1971), pp. 71.106.

18 "Camino oscuro: la novela hispanoamericana contemporánea", Cuadernos -Americanos, 26 (1967), 204-22. 
Quizá la razón de esto quede en lo que Lévi-Strauss nos ha dicho: la edad dorada que buscamos está dentro de nosotros; ${ }^{19}$ o como lo ha dicho Proust en Le temps retroumé (Paris, 1927): "les vrais paradis sont les paradis qu'on a perdus" (p. 12). Como apunta Earle, la dicotomía entre la intención original y la condición última que encontramos en la novela contemporánea (o según yo lo parafrasearía, entre el anti-héroe que es, y lo que él llama el héroe que pudiera haber sido) es un vestigio de la novela picaresca. Esta dicotomía es un rasgo esencial y lo vemos en la igualdad de los dos mundos de Carpentier. Con la posible excepción de Guzmán, ningún pícaro llega al punto deseado. ${ }^{20}$ El pícaro trata de huir de sus fracasos por medio de lo imaginario (como nos sugiere lo citado de Los pasos perdidos), o sea en caso del pícaro, por medio del libro.

Al considerar el viaje como elemento simbólico, no debemos olvidar que el camino es frecuentemente una metáfora (como lo es el mismo viaje) de la vida. Dice Henry Miller que "writing, like life itself, is a voyage of discovery". ${ }^{21}$ Sin duda, toda novela picaresca implica tal concepto moderno de la escritura por medio de la trabazón compleja que existe entre estos cinco conceptos: vida, libro, viaje, escritura, lectura. La vida del pícaro es el viaje a la vez que el libro mismo es ambas cosas, la vida y el viaje. El hecho de escribir es una manera de recorrer de nuevo el trayecto y revivirlo. En sentido figurativo, al leer el lector a su vez vive tal vida y viaja la trayectoria del pícaro. Es claro, pues, que estos cinco términos llegan a ser casi sinónimos en la novela picaresca. ${ }^{22}$

En "El Camino a Santiago" se ve que Carpentier al escribir, y nosotros, al leer, hacemos el viaje con Juan. Hasta cierto punto participamos en su vida ficticia por medio del relato, porque, como dice Sartre en Les mots (París, 1964), basta leer para ser cómplice (p. 64). También se destaca el simbolismo del viaje en este relato por medio de la multiplicidad de sentidos del título. En el nivel más literal, el Camino de Santiago se refiere a la ruta que usaban los peregrinos para llegar a Santiago de Compostela. A la vez alude a la galaxia cuyo antiguo nombre era Vía Láctea. Se nota la dicotomía de las referencias al cielo y a la tierra. En un sentido más figurativo, también se puede entender el Camino de Santiago por el

19 Tristes tropiques (Paris: Librairie Plon, 1955), p. 424.

20 En algunas novelas modernas como Augie March parecen haber llegado, sí, pero su posición es indeseable a causa de la corrupción.

21 "Reflections on Writing", en The Creative Process, ed. Brewster, Ghiselin (New York: New American Library, 1952), p. 178.

22 Esta es relación que nos ha sugerido Céline en sus comentarios al principio de Voyage au bout de la nuit (Paris: Gallimard, 1952). 
camino del Viejo Mundo al Nuevo. Recordemos Santiago de Cuba y el hecho de que Cuba se llamaba oficialmente Santiago durante la época del relato. A la vez, el motivo que atraía a los conquistadores se asemejaba al motivo religioso de la guerra contra los moros en las cuales Santiago animaba a la gente. Apunta Walter Starkie en su libro The Road to Santiago (London, 1957), que muchos de los barcos que venían al Nuevo Mundo traían el nombre de Santiago en las banderas o en la proa (p. 43-4). Cortés mismo invocaba al Santo para que ayudara a sus hombres. ${ }^{23}$ En el sentido religioso, Santiago viajó al Nuevo Mundo: por eso, se puede decir que el camino de Europa a Cuba es otro camino de Santiago. No olvidemos tampoco que la Vía Láctea conduce al oeste. En otro sentido también se ve que el Camino de Santiago es el camino hacia el cielo, hacia la santidad y la vida moral. Quien sigue las huellas del Santo, vive la vida de un santo. Otra vez se nota la dicotomía entre el Camino de Santiago como el camino a las Indias y como el camino hacia la santidad. ${ }^{24}$ Carpentier nos pinta bien, con sus descripciones de la vida depravada en el barco y después con las de la vida en Cuba, que tal ruta está muy lejos del camino hacia la santidad, aunque hay claramente una similaridad en las motivaciones del que busca el cielo y el que procura hallar el Nuevo Mundo, como veremos más adelante. Quizá haya también una relación en el hecho de que, según Starkie, la plaza al norte de la catedral de Santiago de Compostela donde se venden las reliquias religiosas se llama el "paraiso" (p. 70).

IV

Según el color de los siglos cambiaba el mito de carácter, respondiendo a siempre renovadas apetencias, pero era siempre el mismo: había, debía haber, era necesario que hubiese en el tiempo presente - cualquier tiempo presente- un Mundo Mejor. ${ }^{25}$

El tópico del paraíso, además de estar vinculado con el tema constante en Carpentier de "lo real maravilloso", nos lleva al tema de la literatura.

${ }^{23}$ Cartas de relación (México: Porrúa, 1969), p. 101.

24 Es curioso que Starkie ha notado también la dicotomía de la venera, reliquia religiosa que en la épica antigua fue consagrada a Venus por ser considerada emblema de la mujer y lo sexual, op. cit., nota 2, p. 70.

${ }_{25}$ Alejo Carpentier, El siglo de las luces (Barcelona: Seix Barral, 1971), p. 253. 
Como se habrá notado y como lo ha sugerido Roberto González Echevarría en un artículo suyo la obra de Carpentier es siempre basada no en la realidad del día ni en la experiencia propia sino en la literatura. ${ }^{26}$ Es siempre ficción creada de la ficción; arte creado del arte. La base de "El Camino de Santiago" son las crónicas coloniales, y se ve un vínculo muy estrecho entre nuestro protagonista y el cronista (cuya vida y obra no están muy apartadas de las del pícaro). Su deseo de ir al Nuevo Mundo es ocasionado por los fabulosos mitos que circulaban entonces. Al llegar a esta tierra descubre que la vida no es lo que había creído y, cuando está aquí, crea en su mente una vida pasada muy superior a la que la suya realmente fue. De aquí brota el mito del paraíso perdido. El mismo proceso se repite al volver a España y al recordar la vida pasada de América. Así continúa esta tradición mitológica y torna a relatar lo que le habían dicho antes de su salida de España, aunque ya debía saber que no era verdad. He aquí una dramatización de la exhortación de Carpentier en El siglo de las luces: "Cuidémonos de las palabras hermosas; de los Mundos Mejores creados por las palabras" (p. 267). Quizá se puede explicar este procedimiento por la ficción inevitable que resulta del hecho de recordar lo pasado. Como lo han apuntado Sartre y Lévi-Strauss, es imposible recordar sin organizar y seleccionar, y de aquí resulta la ficción, de mayor o menor grado. ${ }^{27}$ En este sentido, lo que hace Juan dramatiza lo que hace cualquier cronista o autobiógrafo; empieza con una verdad y al recordarla y organizarla, labra un cuento, una ficción.

Este tema de la literatura se destaca en varios otros sitios en el relato con menos sutileza. Se alude a las calumnias del Nuevo Mundo, todas las cuales surgen de la escritura; varias veces se refiere a unos dramas y se ve la dificultad en distinguir lo fingido de lo verdadero, o sea la literatura de la vida. También, más de una vez se refiere a la ansiedad de la Inquisición en cuanto a la literatura: ". . no gastaba leña de Inquisición en quemar negros, sino más bien doctores demasiado conocedores del árabe, teólogos de oreja puntiaguda, gente protestante, o difundidores de un librejo hereje, muy perseguido en los puertos donde anclaban las naves holandesas, que tenia por título 'Alabanza de la Locura', o 'Elogio de los Locos', o algo semejante" (p. 61). O sea, la Inquisición reconoce la fuerza de la palabra, una fuerza de la cual el pícaro (y el cronista o cualquier escritor) también toma conciencia. Es por medio

\footnotetext{
26 Véase "Ironía narrativa y estilo en Los pasos perdidos, de Alejo Carpentier", Nueva narrativa bispanoamericana, I, No. 1 (enero 1971), 117-125.

${ }_{27}$ Me refiero a Jean Paul Sartre, La nausée (Paris, 1938) y todo su tratamiento del problema de escribir la historia y de tener una aventura; también, Tristes tropiques ya citado, especialmente p. 28.
} 
de la palabra que el pícaro crea nuevos mundos y se forja nuevas personalidades.

Todos reconocemos el problema que los poderes de la palabra suscita en la perspectiva de la novela picaresca; problema parecido al de la crónica y al presente en "El Camino de Santiago"; nunca se sabe cuándo ni cuánto se debe confiar del narrador o del protagonista. Como dije antes, éste es siempre el problema de las memorias. Sugiero que la perspectiva es especialmente problemática cuando hablamos del pícaro o del

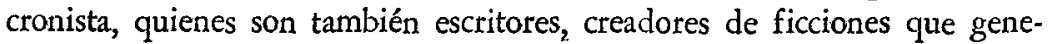
ralmente necesitan justificarse. No es mera casualidad que en la colonia descrita por Carpentier sea el escribano a quien se acuse de pícaro. En este relato me parece que Carpentier ha vinculado el pícaro, el cronista y el escritor; todos emplean la escritura para crear ficciones, $o$, si se prefiere, nuevas realidades, como hace el mismo Carpentier.

Se ve este problema de la perspectiva en la cuestión de la veracidad de lo que dice el protagonista. Es la tesis de Rico (op. cit.) que en la novela picaresca sólo tenemos una perspectiva en vez de una visión total. Carpentier señala varias veces que la perspectiva de Juan cambia según la luz donde se encuentra. Curiosamente es el narrador de Voyage au bout de la nuit quien ha articulado la dificultad de la visión clara en los trópicos: "Il est difficile de regarder les choses des tropiques à cause des couleurs qui émanent. Elles sont en ébullition les couleurs et les choses" (p. 129). Aunque en este cuento no existe el problema del narrador parcial, lo que dice y piensa Juan dentro del relato refleja esta cuestión del prejuicio y de la incapacidad por parte del lector de poder fiarse de lo que dice el protagonista. Es muy típico del pícaro el procedimiento de Juan cuando da a entender a sus compañeros en Cuba que es noble y que era muy buen estudiante. Este hecho es resultado de la necesidad que siente todo pícaro de ser importante y hasta superior; entonces pinta su pasado como mejor de lo que fue. Es curioso notar que Juan se siente superior a los paganos de la isla que no saben más que "aporrear sus bárbaros tambores y cantar unas coplas..." (p. 54) a pesar de que Juan también es tambor y canta.

El motivo de la niebla se repite por todo el relato. En la escena inicial se observa que "todo había de parecerle un tanto aneblado" a causa de la llovizna y añade que estaba "aneblado" por el aguardiente también. Más tarde ve al médico "entre humos". En Bayona con "el vino aligerándole el alma, no ve ya el Campo Estrellado como la noche" de la peste (p. 35). Al llegar al interior de la isla el calvinista y el negro le bajan el sombrero sobre la cara y le hacen caminar "metido en la noche 
de fieltro" (p. 50). Esta repetición parece indicar que Juan, como cualquier pícaro, vive dentro de un tipo de niebla que no le deja ver con claridad. Varias veces en el relato las nubes cubren el Camino de Santiago, y en un sueño, el campanario de la catedral está perdido en las nubes. A causa de esta niebla, el pícaro vive en un tipo de ceguera, la cual no le permite ver más allá de las apariencias, más allá de unas formas vagas, o sea que nunca ve las esencias. Quizá por esta razón, el pícaro depende tanto de las apariencias. Uno también puede preguntarse si, en sentido figurativo, no serían las palabras mismas las que causan esta niebla, que impiden una visión clara. La palabra nos conduce a una imagen del estereotipo en vez de la "realidad"; por medio de la palabra nos inclinamos a ver lo general en vez de lo individual. En este sentido podemos decir que la palabra (instrumento principal del pícaro) entorpece la percepción.

Se puede vincular esta cuestión del punto de vista con la asociación moderna entre el pícaro y el artista. Sin duda la postura del artista siempre tiene qu ser reflejada en su presentación de la "realidad". En obras como Felix Krull, Die Blechtrommel de Günther Grass, y hasta cierto punto en Les faux monnayeurs, hay un nexo muy estrecho entre los engaños del criminal y los del artista (específicamente el escritor). En Les faux monnayeurs, Gide dramatiza tal relación al vincular el que hace monedas falsas y el escritor, el que, por medio de la palabra, crea mundos y personajes falsos que quedan al mismo nivel que la moneda falsa. He aquí lo que hace Juan en "El Camino de Santiago" al relatar su vida pasada a sus compañeros; por medio de la palabra se falsifica.

$\mathrm{El}$ acto de escribir confesiones, sean del santo o del pícaro, sirve varios propósitos. Primero, sirve para que el narrador se mire a sí mismo. El hecho de escribir resulta entonces en otro desdoblamiento: al terminar de escribir su vida, ya existen dos personajes, el que vive, que es persona "verdadera", y el del libro que es una supuesta ficción, una percepción, un conjunto de palabras. ${ }^{28}$ Apunta Sartre en Les mots que al escribir él podía ser "autre": otro que sí mismo (p. 161). También nos dice que "je suis né de l'écriture" y que "écrivant, j'existais" (p. 127). El autobiógtafo (incluso el pícaro, autobiógrafo ficticio), al terminar su obra, ya puede mirarse a sí mismo en forma literaria ( $y$ a veces en la forma en que quiere verse); también, como ya hemos sugerido, al escribir el pícaro torna a vivir lo ya pasado. Este trabajo escrito da a los pícaros ( $y$ aun a un Bernal Díaz del Castillo) un sentido de la identidad que buscan. No pueden decir que son hijos del honrado don Fulano, pero al tomar

28 Aunque en el caso de la novela picaresca los dos son ficciones porque el autor/narrador es también ficticio, la desunión que resulta es igual. 
en sus manos el libro, por lo menos pueden decir "éste, soy yo", y por fin este "yo" es inmortal. También, ser héroe de una novela conlleva cierta cantidad de honra, aunque a veces sea falsa. El libro les da un sentido de importancia, de valor, $y$, al fin, de una posición en la sociedad, porque, por lo menos, son escritores. Este es quizá el propósito más importante. Pero, también insisto en que la maniobra autobiográfica es un acto de ególatra. Como dice la Locura en Elogio de la Locura, el hombre escribe porque desea la gloria y la fama (p. 41). El autobiógrafo escribe porque cree que él y su vida son importantes para el lector, o él espera que él y su vida sean deleitosos y útiles para el lector. El pícaro, como ser egocéntrico, quiere aparecer importainte; de esto se deduce que este ejercicio autobiográfico, como bien lo apunta Heckman (op. cit.), es sencillamente una forma más compleja de la manipulación de disfraces. El pícaro, por medio de la escritura, se está presentando como hombre notable y meritorio, o sea como lo que no es, de la misma manera que presenta su falsedad por medio del vestido o del nombre, porque, como nos ha dicho Sartre, el escritor crea su propio pasado: "Pourquoi donc le passé m'eût-il enrichi? Il ne m'avait pas fait, c'était moi, au contraire, ressuscitant de mes cendres qui arrachais du néant ma memoire par une création toujours recommencée' (p. 197). El hecho de escribir es la última máscara, la última falsificación; es el último esfuerzo para hacerse el hombre de valor que se quiere ser, además de formar lo que Sartre llama una huida de la época y un refugio en este pasado recreado (p. 179). El narrador y el libro mismo son partes del mundo ilusorio, de apariencias, lo cual parece ser evidente en el hecho de que el acto de escribir la novela picaresca siempre existe como parte de la ficción dentro de la ficción total que es el libro y aun el narrador es una ficción a la vez que es una dramatización del escritor "real". Estos diversos niveles de ficción dan énfasis al tema principal de las novelas en que todo es ficción y apariencias; el libro resulta ser lo que Claudio Guillén (op. cit.) llama una dicotomía entre "self-revelation" y "self-concealment".

\section{V \\ "on se reperdait déjà dans les mots" (Voyage au bout de la nuit, p. 498)}

Vamos señalando los varios tipos de máscaras tras las cuales se esconden los pícaros, y no debemos olvidar que el lenguaje forma parte 
principal del disfraz. Hemos ya apuntado el nombre que sirve de máscara al pícaro y que muestra un uso de la palabra como disfraz. Frecuentemente el narrador emplea el lenguaje en forma irónica o satírica, muchas veces queriendo decir lo opuesto de lo que parece. Pensemos en las descripciones del Buscón de sus padres y veremos esta significación doble que sirve para enmascarar: de su madre dice, "todos los copleros de España hacían cosas sobre ella"; de su padre dice, "salió de la cárcel con tanta honra, que le acompañaron doscientos cardenales" (p. 1093). Los juegos de palabras de la pícara Justina en la introducción de su libro también muestran esta ironía que enmascara. Otro ejemplo del lenguaje como máscara serían las digresiones del Guzmár. Como Stuart Miller ha notado éstas forman una especie de laberinto que tiende a confundir al lector a causa de las complejidades verbales por medio de las cuales se enmascara el pícaro. ${ }^{29}$

Puesto que en "El Camino de Santiago" el narrador es un tercero desinteresado, el lenguaje aquí se presta más para desenmascarar que para disfrazar. Este proceso de descubrimiento es muchas veces el resultado de la sátira contra las instituciones sociales o religiosas, como lo apunta Alter (op. cit.). El indiano, con ambigüedad, dice a Juan: "el oro de Indias ha dado término a las lucubraciones de los perseguidores de la Gran Obra. El mercurio hermético, el elixir divino, la lunaria mayor..." (p. 40). $Y$, la fregona observa que la amada del Duque no le atrae como las sirenas de la antigüedad sino que "digan mejor que más tiran dos tetas que dos carretas" (p. 27). En la mayor parte de las novelas picarescas el lenguaje se presta a veces para enmascarar y a veces para desenmascarar. Dice Lazarillo del fraile que "rompía él más zapatos que todo el convento" (refiriéndose a sus andanzas irreligiosas) y "ni yo pude con su trote dutar más" (p. 105). Pensemos también en las críticas de los médicos y de los actores que aparecen en Gil Blas, y en la crítica anti-clerical que se nota en todas estas novelas. A veces la sátira llega hasta el punto de la caricatura y la deshumanización, un recurso muy barroco que se ve en el relato de Carpentier en varios lugares. Por ejemplo, Carpentier se refiere al "gruñido" de la fregona y lo yuxtapone con el "relincho de un garañón", lo cual sitúa a la fregona al mismo nivel que el caballo. Alude a la rata "que debía ser algo así como el abanderado, el pastor hereje, de la horda que corría por los patios..." (p. 29), y observa más tarde que en la feria había "un perro de jubón y gorro" que camina "en las patas traseras, como cristiano" (p. 36). La caricatura del Duque de Alba

29 The Picaresque Novel (Cleveland, 1967), pp. 105-110. 
y su amada es tan grotesca y hasta obscena que pudiera ser una página de Quevedo.

Venía sólo, sin séquito, vestido de negro, con la gola tan apretada al cuello, adelantándole la barba entrecana, que su cabeza hubiera podido ser tomada por cabeza de degollado, llevada de presente en fuente de mármol blanco... El Duque de Alba, sin desarrugar un ceño de quemar luteranos, sacó tres naranjas que le abultaban bajo el entallado del jubón, y empezó a jugar con ellas, a la manera de los titiriteros, pasándoselas de mano a mano, por encima del peinado a la romana, con sorprendente presteza... Y Juan vio salir al Duque de Alba en el viento, tan espigado de cuerpo que se le culebró como cinta de raso al orillar el dintel, seguido de las naranjas que ahora tenían embudos por sombreros, $y$ se sacaban unas patas de ranas de los pellejos, riendo por las arrugas de sus cáscaras. Por el desván pasaba volando, de patio a calle, montada en el mástil de un laúd, una señora de pechos sacados del escote, con la basquina levantada y las nalgas desnudas bajo los alambres del guardainfantes (p. 14).

(Es evidente que la última parte se refiere a la amada por la repetición de la imagen del mástil de un laúd, que resalta antes cuando se habla de ella.) Por medio de la sátira, el narrador picaresco llegaba a uno de los temas más importantes de la novela picaresca, la crítica de la sociedad y de la iglesia.

Finalmente, la novela picaresca desenmascara varios aspectos de la sociedad a la vez que los critica. Aquí al mostrarnos el disfraz del diablo que se coloca en medio del camino santo, Carpentier le quita la máscara: "Y como Belcebú siempre se pasa de listo, he aquí que se disfraza de ciego, vistiendo andrajos, poniendo un gran sombrero negro sobre sus cuernos, $y$, viendo que ha dejado de llover en Burgos, se sube a un banco, en un callejón de la feria, y canta, bordoneando en vihuela con sus larguísimas uñas..." (p. 67). Los últimos párrafos del relato también sitúan el papel del pícaro dentro de su hecho histórico y humano. Se nota la contraposición del diablo y el Santo y la aparente contradicción en que el Santo quiere que estos "pícaros" vayan al Nuevo Mundo para cumplirle aunque es el demonio quien les atrae hacia allí. Es patente que el Nuevo Mundo será fundado por el ser picaresco, porque éste busca su utopía aquí en este mundo, mientras el ser más recto, más religioso espera su 
paraíso más allá en el Cielo y no necesita buscarlo aquí. ${ }^{30}$ El hecho extraño de que Santiago desee que el ser bajo funde estas colonias parece ser explicado en la referencia a los padres del Santo: "Santiago, hijo de Zebedeo y Salomé" (p. 67). Como sería difícil considerar a Salomé una madre ejemplar que asociamos con un santo, nos damos cuenta de la distancia entre los comienzos de Santiago y su punto de llegada. Por consiguiente, podemos esperar que alguna de las obras del picaro (como la fundación de las colonias, incluso la novela picaresca con su ejemplo negativo) resultarán buenas, aunque el pícaro mismo no lo sea. Parece que Carpentier quiere evocar cierta superioridad en este ser picaresco, que no es tan bueno como el hombre religioso pero que, por lo menos, actúa, produce algo: funda colonias; escribe libros; hace algo para mejorar la condición humana en vez de pasar su vida meditando sobre la vida del más allá.

Hay que preguntarse ahora cómo se inserta "El Camino de Santiago" dentro de la colección, Guerra del tiempo. Se ve claramente el tema del tiempo en "Viaje a la semilla" cuando se rompe el orden cronológico, y en "Semejante a la noche" con la repetición de un momento eterno, pero en este relato el tema del tiempo no es tan evidente. El título de la colección, que sugiere que todos los relatos compartan tal tema, viene de una obra de Lope de Vega, Servir a señor discreto, que se ve teflejada en esta obra." ${ }^{31} \mathrm{El}$ epígrafe de la colección, "¿Qué capitán es éste, qué soldado/ De la guerra del tiempo más deshecho/ Que la mar?" (I, 14) se refiere a un don Silvestre, soldado de Flandes hecho indiano como Juan.32 Don Silvestre trata de recobrar su juventud casándose con una mujer joven. El protagonista, don Carlos, otro enamorado de esta mujer joven, había dejado el hábito estudiantil y alcanza llevar el hábito de Santiago. Así, pues, el Juan de Carpentier, por medio de su desdoblamiento, llega a ser un compendio de los dos personajes de Lope: el indiano y el hombre recto, religioso. En el primer acto de la obra de Lope, la pregunta principal que se relaciona con nuestro Juan es "¿Qué camino

30 La relación entre el picaro y el hombre que venía al Nuevo Mundo ha sido mostrada varias veces. Véase Enrique Anderson Imbert, Historia de la literatura bispanoamericana, tomo I (México, 1970), p. 43, y Lewis Hanke, The Spanish Struggle for Justice in the Conquest of America (Philadelphia, 1949), p. 19.

31. Véase Comedias escogidas, tomo 4 (Madrid: Biblioteca de autores españoles, 1860), pp. 70-91.

${ }_{32}$ Lo subrayado es lo que cita Carpentier. He añadido el verso de la comedia que sigue. 
llevaremos?". Pero, a pesar de estos vínculos entre las dos obras, todavía no hemos descubierto el nexo entre el relato de Carpentier y la colección, o sea no hemos enfocado el tema del tiempo.

Cada obra de Carpentier se basa cuidadosamente en unos hechos históricos que se pueden verificar con una investigación cuidadosa; y, ésta no es excepción. Aquí es especialmente importante poder fechar los acontecimientos verificables a causa de consideraciones temáticas. ${ }^{33}$

Sabemos que el Duque de Alba llegó a Flandes en septiembre de 1567, y que empezó lo que se llamó el "tribunal de sangre", que incluyó la ejecución de muchos y la derrota de los tres ejércitos de Guillermo de Nassau, príncipe de Orange, dos acontecimientos sugeridos en la descripción del duque ya citada; ${ }^{34}$ había asegurado la ciudad de Amberes al llegar la primavera de 1568. Pues, cuando la moza del cuento afirma que los cuarteles de invierno en Amberes ya pasaban de cuarteles de primavera (p. 27), podemos fijar la fecha de la acción de los primeros dos capítulos en la primavera de 1568 . En el capítulo tres empieza el peregrinaje de Juan, y al ir viajando se refiere al verano y al principio del otoño con la madurez de las vides. O sea, podemos suponer que al llegar a Burgos en el capítulo crarto, ya se acerca el principio del otoño en 1568.

Ahora bien: en este momento se aparta Juan de su camino santo, va a Sevilla, y espera el mes de mayo para salir al Nuevo Mundo. Queda allí no se sabe cuánto tiempo, y al regresar y acercarse a la Gran Canaria menciona la proximidad del día de la Trinidad (junio). Por eso, podemos suponer que es la primavera otra vez (quizá mayo, lo cual daría una circularidad perfecta al viaje, por salir y volver a Sanlúcar en el mes de mayo). Al fin le encontramos de nuevo en Burgos, y en el último capitulo, al llegar a Valladolid, le "recibe el hedor de un brasero, donde queman la mujer de uno que fue consejero del Emperador" (p. 66). Sin duda esto se refiere a un auto de fe en Valladolid en septiembre de 1568 en el cual la viuda de Herrezuelos, Leonor de Cisneros, fue quemada. ${ }^{35}$

33 Véase R. Trevor Davies, The Golden Century of Spain, 1501-1621 (London, 1937): Antonio Dominguez Ortiz, The Golden Age of Spain: 1516-1659, trans. James Casey (London, 1971); Edward Grierson, The Fatal Inberitance (New York, 1969); Jacobo de la Pezuela, Historia de la isla de Cuba (Madrid, 1868); I. A. Wright, The Early History of Cuba: 1492-1586 (New York, 1916); Ramiro Guerra y Sánchez, José M. Pérez Cabrera, Juan J, Remos, Emeterio. S. Santovenia, eds., Historia de la nación cubana, tomo 1 (Habana, 1952).

34 La referencia a las ejecuciones perpetradas por el duque es evidente. Parece que también se puede inferir una analogía entre las tres naranjas con que juega el Duque (p. 32), y las tropas de Guillermo de Orange. Este dividió su ejército en tres partes que fueron vencidas definitivamente por las tropas del duque.

3.5 Se lee lo siguiente en Marcelino Menéndez Pelayo, Historia de los beterodoxos españoles, tomo II (Madrid, 1880), p. 355: "Por Illéscas sabemos que, 
Entonces, resulta que los capítulos cinco y once son paralelos no sola mente en cuanto a la acción, sino que los dos tienen lugar en el otoño de 1568. Claro que entonces no pudiera haberse llevado a cabo, realísticamente, un viaje al Nuevo Mundo en esos pocos meses, y tenemos que concluir que la obra tiene dos niveles de tiempo al estilo de "Viaje a la semilla" y El acoso en los cuales el tiempo externo señalado en las primeras y en las últimas secciones encuadra un periodo corto de unas cuantas horas, mientras el tiempo interno que se encuentra en las secciones intermedias encuadra un periodo más largo. ${ }^{36}$ De manera análoga, en este cuento las primeras y últimas secciones tratan de un períado de unos meses (de la primavera al otoño) y gran número de los acontecimientos de su vida en el Nuevo Mundo ocurrieron antes que él pudiera haber llegado allí si no hubiera dejado España hasta 1568. Por ejemplo, sabemos que los pasajeros con los cuales se registró en la Casa de Contratación eran hombres verídicas, pero no fueron al Nuevo Mundo en el mismo barco ni tampoco en el mismo año; llegaron entre los años de 1512 y 1935. ${ }^{37}$ En La música en Cuba (México, 1972; primera ed., 1946), Carpentier señala un "Juan de Emberas" que toca el tambor en Cuba en 1557 (p. 53). La serie de chismes que nos da pueden sugerir casi cualquier gobierno de la colonia, pero parecen especialmente indicativos de las décadas de los treinta y los cuarenta. $^{38}$ El otro acontecimiento de América que

en 26 de setiembre de 1568, se hizo justicia de Leonor de Cisneros, mujer del bachiller Herrezuelo, la cual se dejó quemar viva, sin que bastara para convencerla diligencia ninguna de las que con ella se hicieron que fueron muchas..." Véase también lo demás del capítulo 7.

36 Véase Modesto Gaspar Sánchez Camejo. "La elaboración artística de El acoso", tesis Trinity College, 1972.

's7 He encontrado lo siguiente en el Catálogo de pasajeros a las Indias, Vol. 1 (Sevilla, 1940):

\#75 Jácome de Castellón, mercador, hijo de Bernardo de Castellón y de Inés Suárez, vecinos de Toledo-31 mayo 1510.

\#552 Jácome de Castellón, mercador genovés, hijo de Bernardo de Cas. tellón y de Inés Suárez, vecinos de Toledo, que presentó carta de naturaleza; .... (a Castellón volvió a dársele licencia el 15 de julio de este año) -30 abril 1512.

\#1665 Lucia, de color negra, que había sido esclava de Juan Delgado y de Ana de Porras, y ahorrada por ellos_-22 febrero 1514.

\# 1892 El Deán de Nuestra Señora Santa María de Darién-septiembre 1514.

\#3391 Jorge, negro, esclavo que dice que fue del arzobispo de Tarragona, el cual le ahorró y dió por libre-2 septiembre 1527 .

$Y$, en segundo tomo de 1942, encontré:

\#2116 Maese Miguel, pellejero de la Emperatriz-11 agosto 1535.

38 En una carta de L. Vadillo de 1532 (Arch. de Indias de Sevilla, tomo LXXIXX. Col. de Muñoz) se acusa al obispo Miguel Ramírez de usurpar cargos del Inquisidor. También doña Guiomar de Guzmán, pariente del gobernador 
podemos fechar es la matanza de los calvinistas en la Florida por Menéndez de Avilés, la cual turo lugar en 1567.

Lo curioso de estos capítulos intermedios es la mezcla de referencias a los acontecimientos del Nuevo Mundo que hemos fechado arriba, y referencias a acontecimientos de Flandes. Evoca lo de Flandes como si precediera a lo del Nuevo Mundo cuando es al revés. En este sentido el Nuevo Mundo parece existir fuera del tiempo en una especie de presente eterno en el cual no se distingue entre el hoy, el ayer, y el mañana. Afirmando esto, dice el texto que allí se vive "en un tiempo detenido, de mañana igual a ayer, donde los árboles guardan las hojas todo el año, y las horas se miden por el movimiento de las sombras" (p. 53). Y, no es ésta la única vez que sugiere Carpentier tal visión de América. Pensemos en Los pasos perdidos en donde todas las épocas existen simultáneamente en el Nuevo Mundo, y en esta cita de Siglo de las luces que señala el mismo concepto del continente: "porque aqui las gentes estaban como dormidas, inertes, viviendo en un mundo temporal, marginado de todo, suspendido entre el tabaco y el azúcar" (p. 70).

El ver el Nuevo Mundo como un lugar de tiempo detenido del presente eterno, tiene dos corolarios importantes. Ya hemos hablado de desdoblamiento del protagonista, y me parece que podemos aceptar fácilmente que el Romero es el del Viejo Mundo, y al seguir sus pasos seguimos el movimiento del tiempo, mientras el otro Juan, el del Nuevo Mundo, vive fuera del tiempo. Sin embargo, los dos existen simultáneamente tanto como los dos mundos existían y existen sincrónicamente. Segundo, al hablar de las implicaciones del título, ya hemos hablado también de la relación entre la evocación del Cielo, del Paraíso, y la del Nuevo Mundo. Esta relación también existe en cuanto al tiempo. ¿Qué buscaban los conquistadores sino el Dorado y la Fuente de la Juventud? ¿Qué busca el hombre en el Cielo sino una plenitud y un presente eternos? No es mera coincidencia tampoco que Juan nunca ve la Vía Láctea mientras está en el Nuevo Mundo (con excepción del sueño, y aun aquí la ve desde el Viejo Mundo). El que ya vive en un tipo de presente sempiterno no tiene que buscarlo en el Cielo.

En resumen, se ve que sí, "El Camino de Santiago" cabe temáticamente dentro de Grerra del tiempo, y que aquí el tema del tiempo tiene que ver con la evocación del paraíso. Así llegamos de nuevo al tema picaresco. En un artículo suyo, Carpentier ha escrito que lo que los conquistadores

Guzmán, y mujer del gobernador Avilés, fue acusada de comerciar en esclavos en los años cuarenta. En La música en Cuba el mismo Carpentier se refiere a las acusaciones contra Guzmán y su gobierno, p. 25. 
añoraban oscuramente era la felicidad de la infancia, una identificación total con la Madre, asimilada a la Tierra. ${ }^{39}$ Si podemos aceptar que éste es uno de los deseos que motiva a Juan, lo que tenemos en este relato es un fracaso total; fracaso por no haberse asimilado a la tierra del Nuevo Mundo, pues vuelve al Viejo; y fracaso en el plano religioso por dejar el camino santo y nunca conseguir la armonía religiosa. No puede alcanzar armonía y consonancia ni con la tierra ni con Dios. Es esta falta de armonía lo que fuerza a Juan, como al pícaro, a continuar su búsqueda y su viaje para siempre. Juan y el pícaro, a distinción de Esteban en $E l$ siglo de las luces (p. 102), no reconocen la mera ilusión de este camino de San. tiago. Nunca se dan cuenta de que aspiran a "Mundos Mejores hechos de palabras" y que la superstición ha colocado adelante o atrás lo que queda dentro del ser humano. Sin embargo, a diferencia de Juan, el pícaro consigue un tipo de armonía que nunca alcanza Juan porque él escribe su autobiografía y por medio de la escritura (el viaje verbal), alcanza lo que no podía alcanzar por medio del viaje picaresco: llega a detener el tiempo, además de creat y poseer estos "mundos mejores" aunque solamente sean hechos de palabras. Carpentier utiliza los recursos picarescos para expresar las inquietudes que siguen afligiendo al hombre moderno. Sin duda en toda su obra los enigmas del tiempo, del paraíso, y del viaje han seducido a Carpentier; pero, en "El Camino de Santiago" ha añadido dos tópicos contemporáneos (el doble y la escritura) a los que predominaban en el siglo dieciséis: la intranquilidad ante el pícaro y ante el descubrimiento y conquista de América. ${ }^{40}$

SHARON MAGNARELLI

\section{Cornell University}

39 Véase "El mito paradisíaco", El Nacional, 14 de octubre de 1955.

so Quiero expresar mi agradecimiento al Latin American Studies Program de Cornell University por la beca que me facilitó para llevar a cabo este artículo. 